\title{
Aa. Vv., «Cultures Sud», Nouvelle génération. 25 auteurs à découvrir, n. 166
}

Ilaria Vitali

\section{(2) OpenEdition}

1 Journals

\section{Edizione digitale}

URL: http://journals.openedition.org/studifrancesi/9052

DOI: 10.4000/studifrancesi.9052

ISSN: 2421-5856

\section{Editore}

Rosenberg \& Sellier

\section{Edizione cartacea}

Data di pubblicazione: 1 octobre 2008

Paginazione: 496-497

ISSN: 0039-2944

\section{Notizia bibliografica digitale}

Ilaria Vitali, «Aa. VV., «Cultures Sud», Nouvelle génération. 25 auteurs à découvrir, n. 166», Studi Francesi

[Online], 155 (LII | II) | 2008, online dal 30 novembre 2015, consultato il 13 janvier 2021. URL: http:// journals.openedition.org/studifrancesi/9052 ; DOI: https://doi.org/10.4000/studifrancesi.9052

Questo documento è stato generato automaticamente il 13 janvier 2021.

\section{(c) (i) (9)}

Studi Francesi è distribuita con Licenza Creative Commons Attribuzione - Non commerciale - Non opere derivate 4.0 Internazionale. 


\title{
Aa. Vv., «Cultures Sud», Nouvelle génération. 25 auteurs à découvrir, $\mathrm{n}$. 166
}

\author{
Ilaria Vitali
}

\section{NOTIZIA}

«Cultures Sud», Nouvelle génération. 25 auteurs à découvrir, n. 166, luglio-agosto 2007, pp. 167.

1 Questo numero di «Cultures Sud» è imperdibile per chi vuole documentarsi sui nuovi autori che si sono recentemente affacciati sul panorama letterario francofono. Si propone infatti l'obiettivo di presentare venticinque nouvelles plumes, divise per aree geografiche, dall'Africa sub-sahariana all'Oceano Indiano, passando attraverso i Caraibi e il Maghreb. Ad ogni autore è dedicata una presentazione dell'insieme dell'opera a cura di uno studioso, unita ad una scheda dettagliata dell'ultimo romanzo.

Con ben tredici autori, tra i più importanti del panorama francofono attuale, l'Africa nera è senza dubbio quella maggiormente rappresentata. Un articolo iniziale dal titolo Le roman francophone subsahairien des années 2000. Les cadets de la post-indépendance a cura di Papa SAMBA DIOP, sembra far eco al concetto di "post-colonie" utilizzato da Abdourhaman Wabéri in un articolo pubblicato su un numero precedente di "Cultures Sud», allora «Notre Librairie» (Les enfants de la postcolonie. Esquisse d'une nouvelle génération d'écrivains francophones d'Afrique noire, «Notre Librairie», n. 135, 1995, pp. 8-15). Se, come asserisce Samba Diop, la post-indipendenza costituisce per tutti una condizione comune e l'Africa rimane sujet inépuisable, ciò non limita l'apertura degli autori verso l'occidente, tema di diversi romanzi, tra cui Bleu, blanc rouge di Mabanckou o Le prince de Belleville di Beyala. Fatou DIOME, Eugène EBODÉ, Léonora MIANO, NIMROD, Sami тснАK sono solo alcuni dei nomi che questa importante sezione della rivista si propone di presentare al lettore. Il secondo dossier, dedicato ai Caraibi, si apre con un articolo 
introduttivo a cura di Romouald FonKouA, che evidenzia i fenomeni di continuità e rottura nell'opera degli autori della nuova generazione. I Caraibi sono qui rappresentati da quattro autori: Louis-Philippe DALEMBERT, Fabienne KANOR, Kettly MARS e Gary VICTOR, che sottolineano, ognuno con la propria caratteristica voce, la specificità di questo arcipelago fatto di diaspore ed erranze, trasposte sulla carta attraverso un éclatement des codes génériques (p.80), che rende la scrittura stessa meticcia. Rottura nella continuità, i testi di questi nuovi autori non si limitano però all'esercizio stilistico del mélange des genres e, soprattutto, non si interrogano più sull'uso della lingua francese, considerata ormai come un assodato ed efficace mezzo d'espressione. La sezione dedicata al Maghreb, quasi interamente a cura di Khalid zEKRI, si apre con un'introduzione alla letteratura maghrebina del 2000, che evidenzia i fenomeni di continuità e rinnovamento, per poi analizzare in dettaglio le opere di quattro autori: Salim Bachi, Souad Bahéchar, Rajae Benchemsi e Mohamed Hmoudane. Nell'articolo di presentazione, Littératures francophones du Maghreb: les années 2000, Zekri cerca di sottolineare da un lato i temi comuni ai tre paesi comunemente riuniti sotto l'etichetta storica e geopolitica di "Maghreb", senza dimenticare dall'altro le particolarità che le separano. Temi comuni sono il ritorno del subconscio e la presa di coscienza della parola femminile all'interno dello spazio maghrebino. Zekri distingue poi, in modo restrittivo ma non esclusivo, singole specificità: la letteratura algerina continua a testimoniare la tragedia del terrorismo e della guerra civile, pur servendosi del racconto simbolico invece di limitarsi a riprodurre il paradigma del reportage documentario; la letteratura tunisina si interroga maggiormente sulla questione dell'identità culturale, seppur con meno intellettualismo rispetto alla génération des aînés; il Marocco, infine, mette in scena la narrazione del quotidiano e delle sue difficoltà, privilegiando temi come l'omosessualità e l'écriture carcerale. Kumari R. ISSUR, curatrice dell'articolo che introduce il dossier sull'area dell'Oceano indiano, offre qui un assaggio del caleidoscopico panorama letterario di questo "océan de nouveaux souffles", e in particolare delle isole Maurice (ricordiamo che, sulla letteratura di quest'isola, la studiosa ha già curato un numero della rivista «Francofonia», nella primavera del 2005, dal titolo La littérature mauricienne de langue française), Réunion, Madagascar, Comores e Mayotte. "Vivier des talents", quest'oceano ha conosciuto un'autentica renaissance agli inizi del Ventunesismo secolo, come dimostrano le opere degli autori presi in esame: Natacha Appanah, Salim Hatubou, Shenaz Patel e Barlen Pyamotoo.

3 Se alcuni nomi tra quelli citati sono noti non solo ad un pubblico di specialisti, altri faranno sicuramente parlare di sé in futuro. Molti degli scrittori presi in esame in questo numero di «Cultures Sud», tra cui Bachi, Bessora, Beyala, Mabanckou, Mars, Miano, N'dongo, Patel sono stati già tradotti in altre lingue - tra cui l'italiano - ad indicare come il fenomeno letterario di questa giovane generazione si espanda rapidamente oltre i confini geometrici dell'Hexagone. C'è da augurarsi che questi autori non costituiscano solo una «moda» passeggera, ma che sappiano diventare autentiche pietre miliari nel cammino delle letterature francofone. 